\title{
A Paired Sibling Analysis of the Beta-3 Adrenergic Receptor and Obesity in Mexican Americans
}

\author{
Braxton D. Mitchell,, John Blangero, ${ }^{\star}$ Anthony G. Comuzzie, ${ }^{\star}$ Laura A. Almasy, ${ }^{\star}$ Alan R. Shuldiner, ${ }^{\ddagger}$ Kristi Silver, $\$$ \\ Michael P. Stern, $\|$ Jean W. MacCluer, ${ }^{*}$ and James E. Hixson* \\ *Department of Genetics, Southwest Foundation for Biomedical Research, San Antonio, Texas 78245; ${ }^{\ddagger}$ Department of Medicine, Division \\ of Diabetes, Obesity, and Nutrition, University of Maryland at Baltimore, Baltimore, Maryland 21201; ${ }^{\S}$ Department of Medicine, Division

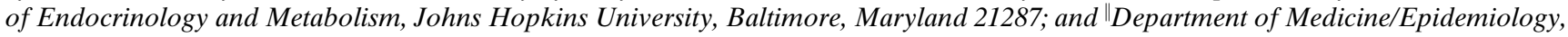 \\ University of Texas Health Science Center, San Antonio, Texas 78284
}

\begin{abstract}
The $\beta_{3}$ adrenergic receptor, located on chromosome 8 , is a regulator of energy expenditure and lipolysis. A missense mutation in this gene, characterized by the replacement of tryptophan by arginine at codon 64 (Trp64Arg), is associated with obesity in some studies. We examined the effect of this variant on obesity in Mexican Americans, using a paired sibling design to minimize variability due to genetic background and a previously identified major susceptibility locus for obesity. We identified 45 sib-pairs that were concordant (identical by descent) for a locus on chromosome 2 which we have shown previously to be tightly linked to obesity in this population. The Trp64Arg variant, detected by PCR-restriction fragment length polymorphism analysis, was present in one sibling within each of the 45 sib-pairs. Presence of the variant was associated with significantly higher values in body mass index $(P=0.04)$, fat mass $(P=$ $0.04)$, and waist circumference $(P=0.05)$. We conclude that the Trp64Arg variant is associated with obesity in this Mexican American population. The paired sibling design probably enhanced our ability to detect the effects of this variant by allowing us to account for variation attributable to another obesity susceptibility locus and to background genes. (J. Clin. Invest. 1998. 101:584-587.) Key words: beta-3adrenoreceptor - obesity - polymorphism • insulin resistance syndrome $\bullet$ genetics
\end{abstract}

\section{Introduction}

Obesity results from a net imbalance between caloric intake and energy expenditure. In humans, obesity is determined by an interplay of both environmental factors and genes (1). The identities of the major genes involved are largely unknown, although the distribution of obesity in some populations suggests

Address correspondence to Braxton D. Mitchell, Ph.D., Department of Genetics, Southwest Foundation for Biomedical Research, P.O. Box 760549, San Antonio, TX 78245-0549. Phone: 210-645-3471; FAX: 210-670-3316; E-mail: bmitchel@darwin.sfbr.org

Received for publication 29 April 1997 and accepted in revised form 5 December 1997.

J. Clin. Invest.

(C) The American Society for Clinical Investigation, Inc. 0021-9738/98/02/0584/04 \$2.00

Volume 101, Number 3, February 1998, 584-587

http://www.jci.org that there may be single loci segregating within families that have relatively large effects on body size or fat mass (2-8).

The $\beta_{3}$ adrenergic receptor $\left(\beta_{3} \mathrm{AR}\right),{ }^{1}$ which maps to the short arm of chromosome 8 , is expressed in adipose tissue and is an important regulator of energy expenditure and lipolysis. Recently, a variant in this gene has been identified that results in a substitution of arginine for tryptophan at codon 64 (Trp64 Arg) (9-11). Some (but not all) studies have reported modest associations between this variant and one or more measures of insulin resistance and obesity, although the inconsistencies between studies have led some investigators to conclude that this variant plays little, if any, role in human obesity (12). If the Trp64Arg variant does influence human obesity, its effects may be relatively small and, in many studies, overshadowed by the effects of other genes. In population-based studies, individuals with and without the Trp64Arg variant may vary considerably with respect to the presence of other susceptibility genes and exposure to other risk factors for obesity. Traditional population-based association studies allow only minimal adjustment for these other influences.

In humans, circulating leptin concentrations are highly correlated with both body mass index and percent body fat (13, 14). We have recently localized a major quantitative trait locus (QTL) influencing serum concentrations of leptin to the small arm of chromosome 2 (chromosome 2p21-23) in a Mexican American population from South Texas (15). Using multipoint linkage analysis, we obtained strong evidence for linkage between serum leptin levels and anonymous marker D2S1788 (lod score $=4.95)$. In our families, this QTL accounted for $47 \%$ of the total variation in serum leptin concentrations and $32 \%$ of the variation in fat mass, as measured by bioimpedance. Thus, this QTL may be a major susceptibility locus for obesity. To account for the effects of this locus, and of other background genetic effects, in our analysis of the $\beta_{3} A R$, we studied sib-pairs who were discordant for the Trp64Arg variant but who were concordant for this major obesity locus on chromosome 2 .

\section{Methods}

Sib-pairs for this study were identified from among participants of the San Antonio Family Heart Study (SAFHS), a genetic epidemiological study of atherosclerosis in Mexican American families (16). A subset of 479 individuals from 10 large families was included in our

1. Abbreviations used in this paper: $\beta_{3} \mathrm{AR}, \beta_{3}$ adrenergic receptor; IBD, identical by descent; QTL, quantitative trait locus; SAFHS, San Antonio Family Heart Study; Trp64Arg, amino acid substitution of arginine for tryptophan at codon 64. 
previous linkage study of serum leptin concentrations and anonymous marker D2S1788 (15). From among these individuals, we identified 89 sib-pairs having a high probability ( $75 \%$ or higher) of being identical by descent (IBD) at the D2S1788 locus. The probability that each pair of siblings was IBD at this locus was estimated using the SOLAR software package developed at our institution (17). The IBD matrix generating program uses a Monte Carlo estimation procedure to sequentially impute missing marker genotypes and then estimates the probability of allele sharing between each pair of relatives using an exact recursive algorithm conditional on the complete data and the estimated allele frequencies (18).

Of the 89 sib-pairs concordant for the D2S1788 locus, 45 were discordant for the Trp64Arg variant at the $\beta_{3} \mathrm{AR}$ (i.e., the Trp64Arg variant was present in one sibling and absent in the other). In only one of these sibling pairs was a sibling homozygous for the Trp64Arg variant; in all other sibling pairs the sibling with the variant was a heterozygote. The 45 sib-pairs included 56 unique individuals (30 with and 26 without the Trp64Arg variant) from 18 different sibships. There were seven sibships of size two, five of size three, four of size four, one of size five, and one of size six.

All subjects received a medical examination in our clinic. Examinations were conducted in the morning, after a 12-h fast. A 2-h oral glucose tolerance test was performed, and diabetes was diagnosed according to the World Health Organization plasma glucose criteria (19). Commercially available radioimmunoassay kits were used to assay serum concentrations of leptin (LINCO, St. Louis, MO) and insulin (Diagnostic Products Corporation, Los Angeles, CA). Anthropometric assessment included measurement of height, weight, subscapular and triceps skinfold thicknesses (measured with Lange calipers), and waist and hip circumferences (measured with a steel tape). Body mass index was defined as weight in kilograms divided by height in meters squared. Two measures of body composition were assessed by bioimpedance (Valhalla Scientific, San Diego, CA): percent body fat, measured as a percentage of total body weight, and fat mass, expressed as kilograms of fat (7). All study procedures were approved by the Institutional Review Board, and all subjects gave informed consent.

The Trp64Arg variant was typed by PCR amplification of leukocyte DNA (forward primer 5'CGCCCAATACCGCCAACAC-3', reverse primer 5'-CCACCAGGAGTCCCATCACC-3') and cleavage with BstN1, as described by Walston et al. (9).

We hypothesized that the mean of the phenotypic differences between sibs (value in the sibling with the variant minus value in the sibling without the variant) was significantly greater than zero. Before analysis, we performed linear regression in the full SAFHS data set to determine the effects of age and sex on each obesity phenotype and then regressed out the effects of these variables on each phenotype. Because diabetes may produce secondary changes in insulin concentrations, subjects with diabetes were excluded from the analyses of insulin.

To evaluate differences between siblings, we used a method conceptually similar to a paired $t$ test, but which allows for the nonindependence among sib-pairs who share a member by generalizing the test to allow for residual genetic covariance among sib-pairs. Estimation of the mean difference between sib-pairs was performed using maximum likelihood. The expected covariance matrix among sibpairs was derived using the delta method (which is exact for linear functions such as the differencing involved in sib contrasts). This matrix allowed for a residual correlation that was jointly estimated as a nuisance parameter. Significance testing of the difference between sib-pairs was performed using likelihood ratio statistics.

\section{Results}

The frequency of the Trp64Arg variant among all participants of the SAFHS was 0.19. Characteristics of the 56 individuals included in this study are shown in Table I. For nearly all of the obesity phenotypes, individuals with the Trp64Arg variant were more obese than those without the variant. The prevalence of diabetes was slightly lower in individuals with the variant than in those in whom the variant was absent, although this difference was not significant $(P=0.33)$. The mean age of diabetes diagnosis was slightly higher in the four individuals with the variant than in the five without (43.8 vs. $35.8 \mathrm{yr}$ ).

Within each sib-pair, the difference in phenotypic values was computed as the value in the sibling with the Trp64Arg variant minus the value in the sibling without the variant. By likelihood ratio test, we then tested whether the mean difference between siblings was significantly greater than zero. The between-sibling differences for each of these measurements were approximately normally distributed. The mean differences in the age- and sex-adjusted obesity phenotypes are shown in Table II. The significance levels obtained by the likelihood ratio test, in which we accounted for the genetic covariation between sib-pairs, tended to be more conservative (i.e., the $P$ values were higher), than those obtained by the paired $t$ test, which assumes that each sib-pair is independent. Ages

Table I. Characteristics of the Study Population According to B3AR Genotype

\begin{tabular}{|c|c|c|c|c|}
\hline & \multicolumn{2}{|c|}{ Males } & \multicolumn{2}{|c|}{ Females } \\
\hline & $\begin{array}{c}\text { Trp64Arg } \\
\text { variant absent }\end{array}$ & $\begin{array}{c}\text { Trp64Arg } \\
\text { variant present }\end{array}$ & $\begin{array}{c}\text { Trp64Arg } \\
\text { variant absent }\end{array}$ & $\begin{array}{c}\text { Trp64Arg } \\
\text { variant present }\end{array}$ \\
\hline$n$ & 15 & 10 & 11 & 20 \\
\hline Age (yr) & $35.3 \pm 14.2$ & $28.8 \pm 9.0$ & $33.7 \pm 10.6$ & $39.0 \pm 14.6$ \\
\hline Diabetes (\%) & 13.3 & 0 & 27.3 & 20.0 \\
\hline $\operatorname{BMI}\left(\mathrm{kg} / \mathrm{m}^{2}\right)$ & $28.5 \pm 3.8$ & $29.4 \pm 3.9$ & $32.0 \pm 5.2$ & $35.3 \pm 10.1$ \\
\hline Waist (mm) & $960.3 \pm 101.9$ & $966.2 \pm 75.8$ & $947.8 \pm 167.6$ & $1058.2 \pm 234.3$ \\
\hline WHR & $0.930 \pm 0.050$ & $0.930 \pm 0.045$ & $0.860 \pm 0.109$ & $0.907 \pm 0.077$ \\
\hline Subscapular/triceps & $2.062 \pm 0.631$ & $2.021 \pm 0.518$ & $1.446 \pm 0.437$ & $1.193 \pm 0.377$ \\
\hline Leptin (ng/ml) & $15.1 \pm 19.5$ & $12.0 \pm 5.3$ & $30.4 \pm 10.8$ & $38.6 \pm 18.1$ \\
\hline ln fast insulin & $2.323 \pm 0.520$ & $2.427 \pm 0.721$ & $2.730 \pm 0.653$ & $2.669 \pm 0.816$ \\
\hline $\ln 2-\mathrm{h}$ insulin & $4.092 \pm 0.539$ & $4.204 \pm 0.671$ & $4.082 \pm 0.881$ & $4.566 \pm 0.884$ \\
\hline Body fat (\%) & $22.9 \pm 5.7$ & $23.6 \pm 5.0$ & $35.1 \pm 5.3$ & $38.5 \pm 9.1$ \\
\hline Fat mass (kg) & $19.4 \pm 6.2$ & $22.1 \pm 5.9$ & $28.2 \pm 7.5$ & $35.6 \pm 17.6$ \\
\hline
\end{tabular}


Table II. Mean Trait Differences in Obesity-related Traits between Siblings Discordant for the Trp64Arg Variant

\begin{tabular}{lccl}
\hline & $\begin{array}{c}\text { Mean inter-sib } \\
\text { difference* }\end{array}$ & $\begin{array}{c}\text { 95\% confidence } \\
\text { interval }\end{array}$ & $P$ value \\
\hline Age & $0.7 \mathrm{yr}$ & $-1.8-3.2 \mathrm{yr}$ & 0.58 \\
Body mass index & $3.0 \mathrm{~kg} / \mathrm{m}^{2}$ & $0.1-5.8 \mathrm{~kg} / \mathrm{m}^{2}$ & 0.045 \\
Fat mass & $6.6 \mathrm{~kg}$ & $0.4-12.8 \mathrm{~kg}$ & 0.043 \\
Percent body fat & $2.8 \%$ & $-0.5-6.2 \%$ & 0.10 \\
Waist circumference & $75.0 \mathrm{~mm}$ & $1.5-148.5 \mathrm{~mm}$ & 0.050 \\
Waist/hip & 0.03 & $-0.01-0.07$ & 0.11 \\
Subscapular/triceps & -0.14 & $-0.33-0.05$ & 0.14 \\
Leptin & $3.9 \mathrm{ng} / \mathrm{ml}$ & $-2.4-10.2 \mathrm{ng} / \mathrm{ml}$ & 0.23 \\
ln (fasting insulin) & 0.14 & $-0.23-0.52$ & 0.45 \\
$\ln$ (2-h insulin) & 0.30 & $-0.15-0.76$ & 0.19 \\
& & & \\
\hline
\end{tabular}

*Value shown represents the mean difference in the age- and sex-adjusted phenotype between the sibling with the Trp64Arg variant and his or her paired sibling without the variant.

were virtually identical between the two paired siblings, with the sibling with the variant on average older by $0.7 \mathrm{yr}$. Presence of the variant was associated with a $3.0 \mathrm{~kg} / \mathrm{m}^{2}$ excess in body mass index $(P=0.045)$, a 6.6 -kg excess in fat mass $(P=$ $0.043)$, and a 75.0-mm excess in waist circumference $(P=$ $0.050)$. There were no significant differences between those with and without the variant in percent body fat, waist/hip ratio, subscapular/triceps ratio, and leptin or insulin levels, although, in general, those with the variant tended also to be more obese by all of these other measures.

\section{Discussion}

Body mass index, fat mass (in kilograms), and waist circumference are all reflections of obesity in this Mexican American population. The correlation among these three measures is high ( $r>0.74$ for each pair-wise comparison), and genes influencing variation in one of these traits are likely to influence variation in the others. It is interesting that the Trp64Arg variant was more strongly associated with the absolute amount of fat mass (expressed in kilograms) than it was with the percentage of body fat. However, the absolute amount of fat mass varies considerably even among individuals of the same height, and previous studies, including two from our own study population $(7,15)$, provide evidence that single genes may have detectable effects on this phenotype $(6-8,15)$.

Previous studies of the effects of the Trp64Arg variant on obesity and insulin resistance have yielded largely inconsistent results. The initial studies, conducted in Pima Indians (9), French (10), and Finns (11), suggested an association between the variant and different aspects of the insulin resistance syndrome, although even in these studies, the effects were not large. The most convincing evidence for an effect of the Trp64 Arg variant was reported in the Finnish study, where heterozygous carriers of the Trp64Arg variant were more likely than subjects without the variant to have multiple features of the insulin resistance syndrome, including higher waist-to-hip ratio, higher diastolic blood pressure, resistance to insulin, and younger age of diabetes onset (11). In the Pimas, no statistically significant differences were observed in any of the pheno- types between heterozygous gene carriers and those homozygous for the wild-type (Arg) variant, although among diabetic individuals, those homozygous for the variant had a significantly younger age of onset than those with either of the other two genotypes (9). In the French study, the Trp64Arg variant was no more frequent in morbidly obese patients than in controls, although among those with morbid obesity, those with the variant reported a significantly greater weight gain since age 20 (10).

More recent studies have provided additional support for a possible effect of the Trp64Arg variant on insulin resistance and obesity, although many inconsistencies remain. In Australians, the presence of the Trp64Arg variant was associated with higher body mass index and diastolic blood pressure in women, but not in men (20). In a Japanese population, the frequency of the Arg variant did not differ between obese and control subjects, although visceral fat area, a more sensitive measure of fat, was significantly greater among those with the variant (21). In two other studies $(22,23)$, individuals homozygous for the Trp64Arg variant had higher body mass indices and were more insulin resistant than other individuals, but no phenotypic differences were observed between heterozygous carriers of the variant and individuals in whom the variant was absent. However, there were only three subjects homozygous for the Trp64Arg variant in one of these studies (23) and ten in the other (22). In other studies, no effect of the Trp64Arg variant could be detected on any of the measured phenotypes (12, 24, 25).

To date, two studies have directly assessed the functional properties of the Trp64Arg $\beta_{3} \mathrm{AR}$ variant. Candelore et al. reported no differences in ligand binding or adenylyl cyclase activation in Chinese hamster ovary cells overexpressing Trp64 or Arg64 $\beta_{3}$ ARs (26). By contrast, Pietri-Rouxel et al. showed decreased ligand-mediated maximal cAMP accumulation of the Arg64 $\beta_{3} A R$ in two different cell lines (27). The reason for the apparent discrepancy between these two studies may reflect differences in methodology, particularly with respect to the levels of receptor expression, which may have masked the ability to detect subtle differences in function. However, $\mathrm{Li}$ and co-workers detected no differences in rates of lipolysis in omental adipocytes of Caucasian subjects who were homozygous for the Trp64 $\beta_{3}$ AR compared with Trp64Arg heterozygotes (28), and Tartaranni and co-workers failed to detect differences between any of the three $\beta_{3}$ AR genotypes and in vivo or in vitro measures of lipid metabolism in Pima Indians (29). Thus, the possibility must be considered that the Trp64Arg variant is a neutral polymorphism that is in linkage disequilibrium with some other mutation, perhaps in the $\beta_{3} \mathrm{AR}$ or a nearby gene, that influences obesity.

Numerous genes are likely to contribute to obesity, although the multiple loci involved may include one (or several) with moderate to large sized effects. In our Mexican American population, a locus mapping to chromosome 2p21-23 may be one such major locus. Possibly, the power of our study to detect an effect of the Trp64Arg variant was enhanced by our ability to match Trp64Arg positive and negative subjects for the presence or absence of this other major obesity susceptibility major gene. Because siblings share both a common familial environment and $\sim 50 \%$ of their genetic background with each other, other background differences in obesity risk factors were further minimized in our sample. Thus, to the extent that extraneous sources of variation between siblings can be 
removed, the paired sibling design can be a very efficient approach for evaluating the effects of candidate genes in complex human diseases.

\section{Acknowledgments}

We are deeply grateful for the cooperation of the families participating in the SAFHS. The authors would like also to thank Patricia Powers for her excellent technical assistance.

This work was supported by grants PO1-HL45522, RO1DK49692 (A.R. Shuldiner), and 1F32-DK09340 (K. Silver) from the National Institutes of Health, and by the American Diabetes Association (A.R. Shuldiner) and the Paul Beeson Physician Faculty Scholar Program of the American Federation of Aging Research (A.R. Shuldiner).

\section{References}

1. Bouchard, C., and L. Pérusse. 1993. Genetics of obesity. Ann. Rev. Nutr. 13:337-354.

2. Price, R.A., R. Ness, and P. Laskarzewski. 1990. Common major gene inheritance of extreme overweight. Hum. Biol. 62:747-765.

3. Moll, P.P., T.L. Burns, and R.M. Lauer. 1991. The genetic and environmental sources of body mass index variability: the Muscatine Ponderosity Family Study. Am. J. Hum. Genet. 49:1243-1255.

4. Borecki, I.B., G.E. Bonney, T. Rice, C. Bouchard, and D.C. Rao. 1993. Influence of genotype-dependent effects of covariates on the outcome of segregation analysis of the body mass index. Am. J. Hum. Genet. 53:676-687.

5. Rice, T., I.B. Borecki, C. Bouchard, and D.C. Rao. 1993. Segregation analysis of body mass index in an unselected French-Canadian sample: the Québec family study. Obesity Res. 1:288-294.

6. Rice, T., I.B. Borecki, C. Bouchard, and D.C. Rao. 1993. Segregation analysis of fat mass and other body composition measures derived from underwater weighing. Am. J. Hum. Genet. 52:967-973.

7. Comuzzie, A.G., J. Blangero, M.C. Mahaney, B.D. Mitchell, J.E. Hixson, P.B. Samollow, M.P. Stern, and J.W. MacCluer. 1995. Major gene with sex-specific effects influences fat mass in Mexican Americans. Genet. Epidemiol. 12: $475-488$

8. Lecomte, E., B. Herbeth, V. Nicaud, R. Rakotovao, Y. Artur, and L. Tiret. 1997. Segregation analysis of fat mass and fat-free mass with age- and sexdependent effects: The Stanislas Family Study. Genet. Epidemiol. 14:51-62.

9. Walston, J., K. Silver, C. Bogardus, W.C. Knowler, F.S. Celi, S. Austin, B. Manning, A.D. Strosberg, N. Raben, J.D. Sorkin, et al. 1995. Time of onset of non-insulin-dependent diabetes mellitus and genetic variation in the b3-adrenergic receptor gene. N. Engl. J. Med. 333:343-347.

10. Clemént, K., C. Vaisse, B.S.J. Manning, A. Basdevant, B. Guy-Grand, J. Ruiz, K.D. Silver, A.R. Shuldiner, P. Froguel, and A.D. Strosberg. 1995. Genetic variation in the $\beta_{3}$-adrenergic receptor and an increased capacity to gain weight in patients with morbid obesity. N. Engl. J. Med. 333:352-354.

11. Widén, E., M. Lehto, T. Kannen, J. Walston, A.R. Shuldiner, and L.C. Groop. 1995. Association of a polymorphism in the $\beta_{3}$-adrenergic-receptorgene with features of the insulin resistance syndrome in Finns. N. Engl. J. Med. 333:348-351.

12. Maurieg, P., and C. Bouchard. 1996. Trp64Arg variant in $\beta_{3}$-adrenoreceptor gene of doubtful significance for obesity and insulin resistance. Lancet.
348:699-700.

13. Maffei, M., J. Halaas, E. Ravussin, R.E. Pratley, G.H. Lee, Y. Zhang, H. Fei, S. Kim, R. Lallone, S. Rangganathan, et al. 1995. Leptin levels in humans and rodent: measurement of plasma leptin and $o b$ RNA in obese and weightreduced subjects. Nat. Med. 1:1155-1161.

14. Considine, R.V., M.K. Sinha, M.L. Heiman, A. Kriauciunas, T.W. Stephens, M.R. Nyce, J.P. Ohannesian, C.C. Marco, L.J. McKee, T.L. Bauer, and J.F. Caro. 1996. Serum immunoreactive-leptin concentrations in normalweight and obese humans. N. Engl. J. Med. 334:292-295.

15. Comuzzie, A.G., J.E. Hixson, L. Almasy, B.D. Mitchell, M.C. Mahaney, T.D. Dyer, M.P. Stern, J.W. MacCluer, and J. Blangero. 1997. A major quantitative trait locus determining serum leptin levels and fat mass is located on human chromosome 2. Nat. Genet. 15:273-276.

16. Mitchell, B.D., C.M. Kammerer, J. Blangero, M.C. Mahaney, D.L. Rainwater, B. Dyke, J.E. Hixson, R.D. Henkel, M.R. Sharp, A.G. Comuzzie, et al. 1996. Genetic and environmental contributions to cardiovascular risk factors in Mexican Americans: The San Antonio Family Heart Study. Circulation. 94: 2159-2170.

17. Blangero, J., and L.A. Almasy. 1996. SOLAR: Sequential Oligogenic Linkage Analysis Routines. Technical notes. Population Genetics Laboratory, Southwest Foundation for Biomedical Research, San Antonio, TX.

18. Davis, S., M. Schoeder, L.R. Goldin, and D.E. Weeks. 1996. Nonparametric simulation-based statistics for detecting linkage in general pedigrees. Am. J. Hum. Genet. 58:867-880.

19. World Health Organization Expert Committee. 1980. Second Report on Diabetes Mellitus. Geneva, Switzerland: World Health Organization. Technical Report Series, No. 646.

20. Kurabayashi, T., D.G.P. Carey, and N.A. Morrison. 1996. The $\beta_{3}$-adrenergic receptor gene trp64arg variant is overrepresented in obese women: effects on weight, BMI, abdominal fat, blood pressure, and reproductive history in an elderly Australian population. Diabetes. 45:1358-1363.

21. Sakane, N., T. Yoshida, T. Umekawa, M. Kondo, Y. Sakai, and T. Takahashi. 1997. $\beta_{3}$-adrenergic receptor polymorphism: a genetic marker for viscera fat obesity and the insulin resistance syndrome. Diabetologia. 40:200-204.

22. Fujisawa, T., H. Ikegami, E. Yamato, K. Takekawa, Y. Nakagawa, Y. Hamada, T. Oga, H. Ueda, M. Shintani, M. Fukuda, and T. Ogihara. 1996. Association of Trp64Arg variant of the $\beta_{3}$-adrenergic receptor with NIDDM and body weight gain. Diabetologia. 39:349-352.

23. Urhammer, S.A., J.O. Clausen, T. Hansen, and O. Pederson. 1996. Insulin sensitivity and body weight changes in young carriers of the codon 64 amino acid polymorphism of the $\beta_{3}$-adrenergic receptor gene. Diabetes. 45:1115-1120.

24. Awata, T., and S. Kaayama. 1996. Genetic variation in the $\beta_{3}$-adrenergic receptor in Japanese NIDDM patients. Diabetes Care. 19:271-272.

25. Elbein, S.C., M. Hoffman, K. Barrett, K. Wegner, C. Miles, K. Bachman, D. Berkowitz, A.R. Shuldiner, M.F. Leppert, and S. Hasstedt. 1996. Role of the beta-3-adrenergic receptor in obesity and noninsulin-dependent diabetes among members of Caucasian families with a diabetic sibling pair. J. Clin. Endocrinol. Metab. 81:4422-4427.

26. Candelore, M.R., L. Deng, L.M. Tota, L.J. Kelly, M.A. Cascieri, and C.D. Strader. 1996. Pharmacological characterization of a recently described human beta3-adrenergic receptor mutant. Endocrinology. 137:2638-2641.

27. Pietri-Rouxel, F., B.S. Manning, J. Gros, and A.D. Strosberg. 1997. The biochemical effect of the naturally occurring Trp64 $\rightarrow$ Arg mutation on human beta3-adrenoceptor activity. Eur. J. Biochem. 247:1174-1179.

28. Li, L.S., F. Lönnqvist, H. Luthman, and P. Arner. 1996. Phenotypic characterization of the Trp64Arg polymorphism in the beta3-adrenergic receptor gene in normal weight and obese subjects. Diabetologia. 39:857-860.

29. Tataranni, P.A., R. Pratley, A. Shuldiner, and E. Ravussin. 1997. Beta 3-adrenergic receptor gene variant and lipid metabolism in Pima Indians. Diabetologia. 40:123-124. 